\title{
THE FUNCTIONS OF CODE SWITCHING IN ENGLISH LANGUAGE LEARNING CLASSES
}

Christa van der Walt

Stellenbosch University

It has been a cornerstone of English language teaching, as well as a proud tradition, that English should be taught by using only English. The practice is not questioned often and student teachers remember and are sometimes reminded during their practical teaching sessions of various techniques and strategies that can be used to get learners to speak English only, from pretending to be deaf when learners address them in their home language to punishing learners by exacting a 'fine' of some sort when they 'lapse' into their home languages. Auerbach (1993), Swain and Lapkin (2000), Cook (2001) and Hughes et al. (2006) discuss the resistance against the use of home or community languages in language teaching classes and describe a variety of functions for which languages other than the target language can be used with good effect. The question in this article is whether English language teaching practices in a number of Western Cape schools demonstrate similar functions of code switching.

\section{INTRODUCTION}

Imagine the following: a class of 10-year olds, in their fourth year of learning English. The teacher is an enthusiastic pre-service student who teaches her first real lesson to real children. With much enthusiasm she takes them through the first part of her lesson and then puts them in groups to complete a task. The whole class is buzzing as the children organise words and sentences on cards and negotiate with each other as to who should do what. Then they hear the dreaded words: "Remember, this is an English class. We use only English!" The communication stops. The group work is completed in virtual silence with whispers and hand signals.

The tenet that English should be used exclusively by teachers and learners is such a widespread one that teacher trainees start their education studies with this idea firmly entrenched. They can provide a wide variety of strategies, from quite ingenious to downright cruel, of how the teacher can enforce this practice, even with beginner learners.

The first question one should ask about code switching when teaching English is why there seems to be such widespread resistance to using other languages in the English language classroom? Cook (2001:403) calls this an example of the basic assumptions in language teaching "that are rarely discussed or presented to new teachers but are taken for granted as the foundation of language teaching". Auerbach (1993:8) cites a number of sources to support her claim that, "[h]istorically, code switching has been discouraged in the educational 
system and society at large because of concerns that code switching will influence one or both of the languages and lead to language decay ... or because of a perception that code switching is considered a sign of limited language proficiency ... it is perceived most negatively by monolingual speakers and majority cultural and generational groups in terms of understandability, attractiveness and correctness".

South African case studies confirm these perceptions. Setati et al (2002) describe schools in Kwa-Zulu Natal where teachers thought that code switching just was not allowed; Van der Walt, Mabule and de Beer (2001) observed classroom code switching in a secondary school in Mamelodi (Gauteng) where the principal assured the researchers that code switching does not happen in his school. These examples from across South Africa show a general resistance to code switching, which is resisted even more when English is taught as a subject. Cummins (2008) in a keynote address at a conference on English medium universities talks about the invisible signal at the entry to the English language classroom. The signal reads "Check your home language here".

In the southern African context classroom code switching is an important topic and the practice is widespread, specifically in schools where the majority of teachers and learners use other languages alongside a former colonial language. I have argued (with others) since 1997 (Van der Walt, 1997; Van der Walt et al. 2001) that code switching should be acknowledged as a powerful resource so that its use in classrooms can be formalised and included in teacher training courses to ensure its responsible use as a teaching tool. Ferguson (2006:193) agrees by identifying code switching as a useful resource to "ameliorate" the difficult situation of using a foreign language as a medium of instruction. He concludes (Ferguson, 2006:193) that " $[\mathrm{t}]$ here is a good case, then, for moderating official hostility to CS, for acknowledging its prevalence and, indeed, for incorporating awareness of CS as a resource into teacher education curricula". In section 5 this article hopes to provide some guidelines that may be incorporated into the training of English language teachers.

The second question that one should ask about code switching in instructional settings in general is about the usefulness of current descriptive frameworks to explain this phenomenon. The nature of communication in the classroom differs from multilingual social settings that are normally described in Sociolinguistic studies of code switching. Classroom code switching can probably be located on a continuum with formal teacher talk and very deliberate switching at the one end (furthest away from conversational code switching) and small group interaction at the other end (overlapping with conversational code switching). The kind of code switching referred to in this study includes direct oral translations (interpretations), borrowings and switching between clauses and sentences. The teacher, as manager of the classroom and the one who mainly determines the pace and nature of the pedagogical conversation and who manages turn-taking, will direct classroom communication in a formal way and her communication with learners will differ from the situation where learners communicate more informally with each other in the process of completing a classroom assignment. As Seedhouse (2005:174) himself indicates with reference to a study done in collaboration with Üstünel, "codeswitching in L2 classrooms is orderly and related to the evolution of pedagogical focus and sequence". This kind of interaction is similar to what Becker-Mrotzek and Vogt (2001:160) call "ritualized forms of interaction". The patterns and themes identified in sections 3 and 4 provide a glimpse into the 'orderliness' of current code switching practices in English language teaching classrooms. However, an understanding of code switching depends on an understanding of the context in which it takes place, which will be the focus of the next section. 


\section{THE CONTEXT OF THIS STUDY}

\subsection{The policy context}

The Language in Education Policy (1997) supports "an additive approach to bilingualism ... as the normal orientation of our language-in-education policy". Schools have to develop a language in education policy and this is the specific responsibility of the school governing body, which "must stipulate how the school will promote multilingualism through using more than one language of learning and teaching, and/or by offering additional languages as fullyfledged subjects, and/or applying special immersion or language maintenance programmes, or through other means approved by the head of the provincial education department". This background is of particular importance for the schools referred to below because in some cases their policies have changed from one language of instruction to another.

The generic curriculum statement for the Learning area Language, Literacy and Communication (1997) encourages awareness and use of other languages by raising awareness of the status and power of different languages (1997:30), by encouraging learners to compare the structure of different languages (1997:36) and by translating from one language to another (1997:38). Of particular importance for this study is the particularisation of the generic curriculum statement for English First Additional Language and the space allocated to code switching, since this is the curriculum that most South African learners will follow with a view to using English as a language of learning and teaching at some stage in their education.

Although a paragraph supporting an additive multilingual approach appears in the GET and FET Home Language, First Additional Language and Second Additional Language curriculum statements ${ }^{i}$, the use of a home- or community language is referred to mainly in Grade 1, and as a condition when the first additional language is used as a language of learning and teaching: "The home language should continue to be used alongside the additional language for as long as possible" (Revised National Curriculum Statement [RNCS] Grades R-9, 2002:5). For the intermediate phase code switching is allowed "when discussing complex issues such as the social and ethical dimensions of a story, or when comparing the grammar of their home and additional languages" (RNCS Grades R-9, 2002:48). Assessment standards that allow for code switching are specified for grades 4 and 6 and translation activities (telling stories from the home language in English) appear in grades 7 and 9. Critical language awareness, specifically with a view to accommodating cultural and social differences and avoiding stereotyping (RNCS Grades R-9, 2002:59-61,94-95) may also lead to code switching, although this is not mentioned explicitly. In the National Curriculum Statement (NCS) for FET (2003:12) the overarching outcome to develop oral proficiency includes the ability to "recognise and use appropriate oral genres and registers in a range of formal and informal contexts", which could include discussions about code switching. A grade 10 learner has to demonstrate the ability to use language structure and conventions appropriately, referring to a home language to "translate short sentences from target language into home language and vice versa" (NCS English First Additional Language (2003:42), which is extended to sentences and paragraphs for grades 11 and 12 (2003:43). The standards by means of which critical language awareness is assessed in the FET phase are similar to those for the GET (with obvious changes in the level), with the addition of an awareness of language varieties. 
Although there is space, albeit limited, for code switching practices in the curriculum statements, resistance to this practice in language teaching in particular still prevails to the extent that researchers like Auerbach (1993), Swain and Lapkin (2000), Cook (2001) and Hughes et al. (2006) feel the need to defend its use.

\subsection{The Western Cape context}

The Western Cape has three main home languages, with Afrikaans used by 59\%, isiXhosa by $24 \%$ and English by $19 \%$ of the population polled in the 2001 census (at statssa.gov.za). When the distribution of home languages in urban areas are contrasted with rural areas, where the schools reported on in this study are located, it is clear that Afrikaans is spoken more widely in the rural areas: $79.8 \%$ of Afrikaans speakers, $14.9 \%$ of isiXhosa and $4 \%$ of English speakers live in the rural areas (Plüddeman et al., 2004:27). As a result of their privileged position during the Apartheid regime, Afrikaans and English are the only languages used as languages of learning and teaching beyond grade 4. However, since 1994 a major shift has occurred in Afrikaans communities and schools, with schools either moving towards English or running parallel- or dual-medium systems. In their survey of language practices Plüddeman et al. (2004:9) conclude that, "English is becoming increasingly dominant in the Cape Town metropolis, and is also beginning to make inroads into the traditionally Afrikaans-dominant platteland". The power and status of English is evident here as well as the privileged position of Afrikaans and one can only agree with Plüddeman et al. (2004:60) that, "[t]aken as a whole, language learning practices represent a continuation of the apartheid-era practice of valorising English/Afrikaans bilingualism at the expense of African languages".

The schools represented in this project reflect the changes in language preferences of mainly white and so-called coloured communities. Twelve secondary schools and four primary schools are included in this study. Five of the secondary schools have explicitly AfrikaansEnglish bilingual education policies and even where the model is parallel medium (which would imply a separation of the two languages) teacher trainees report code switching by the teachers and learners as ubiquitous and 'normal' (reported below). Of the remaining seven secondary schools two are schools in former 'coloured' communities and both changed from Afrikaans to English as language of learning and teaching in the recent past. Teachers still know Afrikaans and the majority of the learners still seem to come from communities that use Afrikaans at home. Three of the schools are Afrikaans-medium (government) schools, two are English-medium private schools and one is a former model C, English-medium school.

Of the primary schools one is Afrikaans-medium, and the second used to be Afrikaansmedium that changed recently to English-medium. This school is on the border with the local township where isiXhosa is dominant and the influx of learners who do not understand Afrikaans led to this change. The third primary school is located in a former township and uses isiXhosa for the first four years of school, switching to English afterwards, and the fourth is a primary school with an Afrikaans-English bilingual policy (parallel medium) ${ }^{\mathrm{ii}}$.

Although the majority of the schools are, therefore, Afrikaans-dominant, code switching to Afrikaans (from English) and to English (from Afrikaans) and from English to isiXhosa and back occurred in the English-medium schools as well as in the one primary (isiXhosadominant) school. 


\section{METHODS AND PROCEDURES}

For a study on code switching in these education contexts the language policy of the school, its recent history as well as the composition and language proficiency of the teachers are important factors. However, the focus in this article is on the general patterns and functions of code switching in the exploratory phase of a project on English language teaching in multilingual contexts. For that reason the particular instances of code switching are compared to those identified in existing studies in an effort to identify areas that will yield rich data upon further enquiry. This approach is similar to that described by Lofland (2002:146) for analytic ethnography, where "the effort is to lift the situation under study out of its historically specific details and to place it among the array of matters of interest to broad audiences".

The data for this project were collected in the third quarter of 2007 and 2008 when BEd (focusing on grades 6-9) and PGCE students (focusing on grades 8-10) do their practical teaching in schools in the Stellenbosch, Somerset West, Paarl and Franschhoek area. There are two sets of data: the first set was collected by me (using an observation schedule, see Table 1 below) in the course of observing students' lessons in 2007 and 2008. The focus was mainly on examples of code switching, noted with the context in which it took place.

Table 1

\begin{tabular}{|l|l|}
\hline Student name: & Home language: \\
\hline School: & Medium of instruction of school: \\
\hline Grade: & Class composition (gender): \\
\hline Teacher examples of code switching: & \\
Learner examples of code switching: & \\
\hline
\end{tabular}

The examples of code switching were noted in the order they occurred in the course of the lesson with no attempt to identify functions at this point.

The second set was collected by the PGCE students in the same two years as part of a research assignment. In this data set the students observed the teachers and learners in whose classes they were placed (grades 8-11). The assignment was a collaborative effort with a colleague who taught a module in educational research and we wanted students to apply certain research techniques and research ethics in their curriculum specialisation areas. Students specialising in English language teaching were required to do classroom observations and report on the results along the following lines:

Observe the degree to which teachers in the school use code switching when they teach. You need not limit your observation to English language classes. How much do they code switch? Why do they do it?

The above question was one of three that they could choose from and they were advised to take their time before making a choice, since I knew from previous years that code switching is limited in some schools and may not provide enough data for the purposes of a research assignment. Although students who chose the code switching topic need not have limited their observations to English languages classes, the ones who wrote this assignment focused mainly on such classes since they taught at Afrikaans-medium schools or schools that were Afrikaans-medium in the recent past or schools with a bilingual education policy. The choice of topic in these contexts is significant since home- and community languages are ever present. (See further discussion below.) 
My field notes were compared to the data collected by the PGCE students (see below). The code switching samples were only categorised in terms of their functions at the point when all the data could be compared across the different data sets by following the three-tiered analytic process for qualitative data as described by Miles and Huberman (1994:92): preparing the data, identifying themes and categories, and finally synthesizing the common trends and patterns.

In the discussion that follows I will report on the code switching practices of student teachers and practising teachers as well as their learners under two headings: code switching that is intended to develop language competence in English, and code switching that serves affective purposes, either to converge or diverge (in terms of Accommodation Theory) from other speakers. The data is then synthesized (Miles and Huberman, 1994:92) and the code switching practices of South African teachers and learners in English language teaching classes will be compared to those described by Auerbach (1993), Swain and Lapkin (2000) and Hughes et al. (2006) to determine the extent to which code switching serves similar purposes in South African, English language teaching classes in particular. The article will be concluded by reflecting on the degree to which such practices are judged to be successful - in terms of mediating complex concepts as well as decreasing the distance between learner and teacher, thus answering the first question mentioned in section 1 . The fact that patterns and trends emerge from the data, points towards possible guidelines for English language teacher education and training, providing a starting point by means of which the answer to the second question (section 1) can be tackled.

\section{FUNCTIONS OF CODE SWITCHING AS OBSERVED IN CLASSROOMS}

The majority of student teachers who decided to tackle the code switching topic each year were students who were placed at the kind of schools described in section 2. Some of them were English-dominant bilinguals and the BEd students have some knowledge of isiXhosa. One student, a home language speaker of sePedi, is also fluent in isiXhosa. Undergraduate students at Stellenbosch University are expected to be bilingual with at least receptive skills in either English or Afrikaans and the postgraduate students involved in this study are also bilingual. The fact that they chose the code switching topic is already significant (as mentioned before) since their focus on the topic seems to agree with Mati's view (2004:21) that this kind of classroom language use is regarded as 'normal' in bi/multilingual contexts. Students' choice of the code switching topic also shows the focus on school contexts where English is taught mainly as a first additional language or as a primary language to non-home language speakers, particularly at Afrikaans or bilingual education schools. However, code switching also takes place in schools that use only English as the medium of instruction to accommodate L2 learners, particularly schools that switched only recently from Afrikaans to English as the sole medium of instruction.

In the discussion below I will refer to students by their names only to protect their identity. The fact that the data were collected in two consecutive years, mainly in the same schools, provides a degree of validity and trustworthiness. In the discussion below I will also indicate the degree to which my own observations agree with those of the student teachers.

Students who taught at English-medium private schools did not report on code switching practices. They claim that it does not happen at such schools because learners are only taught 
English as a primary language. From my own observations this seems true to a certain extent, although the learners in these schools are by no means exclusively home language speakers of English.

Auerbach (1993:20), making the case for code switching as a tool to develop proficiency in English, provides an overview of research that identifies situations where code switching "reduces anxiety and enhances the affective environment for learning, takes into account sociocultural factors, facilitates incorporation of learners' life experiences, and allows for learner-centered curriculum development". I will focus my discussion firstly (4.1) on data that demonstrate code switching practices intended to clarify meaning and make sense of the curriculum and secondly (4.2) on affective factors where inclusion or exclusion is effected by means of code switching. This division is based on my own observations and on those provided by the PGCE student teachers, neatly summarized by one of them who observed that "the teacher only code switched in two scenarios: either when she tried to explain a difficult term to the learners, or when she wanted to get a special message across, like when she was scolding the class or an individual learner" (Lize PGCE).

\subsection{Code switching that intends to clarify meaning and develop English language competence}

A list of code switching practices that emerge from Auerbach's (1993:21) overview of research identifies code switching practices to negotiate the syllabus and the lesson, set the scene, provide instructions or prompts, explain errors and assess comprehension. These functions are confirmed by Tarone and Swain (1995), who describe immersion classroom settings at primary school level as a diglossic situation with learners using the language of learning and teaching mainly for academic topics and their home or community languages for more social-oriented purposes. In a 2000 study, Swain and Lapkin (2000:268) demonstrate how learners in group work use their L1 "to understand and make sense of the requirements and content of the task; to focus attention on language form, vocabulary use, and overall organization; and to establish the tone and nature of their collaboration".

This kind of interaction by full-time and student teachers with learners as well as among learners in groups was observed in differing degrees in the intermediate and senior phases of the GET as well as in the FET phases. At the simplest level I observed student teachers providing an Afrikaans explanation for a difficult English term (without any indication from the learners that they did not know the meaning of the word) or providing the Afrikaans equivalent when they saw that learners did not understand. Although student teachers are normally encouraged to make learners guess the meaning of a word from its context or to look up the word in a dictionary, they are generally under pressure to finish a lesson within a time limit and are therefore loathe to take the extra time for just one word. One of the student teachers disapprovingly calls this a "quick fix" attitude to code switching (Renier PGCE). Another student teacher who did her practical teaching at the same school as Renier (a year earlier) also observed the use of Afrikaans for difficult terms up to grade 10 level (Yvette PGCE).

The fact that learners encounter Afrikaans home language work that is similar to English, makes it possible for the teacher to depend on their knowledge in that language to develop English language competence, as Lize (PGCE) explains: "When the teacher did this work with the grade $8 \mathrm{~s}$ [the first year of secondary school], it was clear that they struggled to grasp 
the meaning. But when the teacher then explained that a simile is called a "vergelyking" in Afrikaans, and that you use 'like' or 'as' in a simile just like you use "soos" in a "vergelyking", you could immediately see how their understanding of the term grew."

Providing a single lexical item to clarify meaning happens particularly when grammatical terms are used. Janelle (PGCE) reports that a teacher who is against code switching in English language classes conceded that "the use of code switching might be advantageous to explain grammar rules, and other aspects that has (sic) to do with the framework of the English language, in a language that the learners readily understand". Another student noted that a teacher, who also qualified to teach Afrikaans, used her knowledge of that grammar system and "if she saw that the learners could not grasp the concepts, she would use an example of Afrikaans language studies in order to make it understandable for the learners, afterwards she would switch back to English" (Phoebe PGCE).

Such a strategy can only be used when the languages have a similar grammatical structure and therefore this happens mostly in Afrikaans-medium schools or schools where the teacher can depend on the learners being taught their home language as a primary- or first additional language, since the syllabus requires the teaching of grammar terminology for both these curricula. When the learners' home language is taught as a second additional language (e.g. a Xhosa-speaking learner in an English-medium school) the focus is mainly on oral communicative proficiency. In this case a comparison may have been difficult even if learners followed the primary or first additional language curriculum, since the Xhosa grammar system is not directly comparable like English and Afrikaans, for example. Even in the case of Afrikaans learners in the English language class, one student observes that "she [the practising teacher] only translates English words that are closely related to their Afrikaans equivalents" (Irene PGCE). My own observations included the example, "Add a suffix, agtervoegsel in Afrikaans,..." (using air quotation marks, Eloïse BEd), in which case the English word is not close to Afrikaans.

Both student teachers and practising teachers are willing to let learners use their home language when they have to respond and seem to get into trouble. I observed a class of Afrikaans-speaking Grade 8 English FAL learners where the learners who could not say something in English whispered their contribution to a friend who would then translate the request or answer. In the discussion with the student teacher afterwards she confirmed that the teacher established a practice where learners are allowed to do this regularly (Irene, PGCE). This practice resulted in a collaborative effort with both learners trying to come up with the right word or phrase. Mari (PGCE) reports from an Afrikaans-medium, former model C school, that the teacher in an English home language classroom never code switches but that learners who are ESL speakers following the home language curriculum, regularly say "Ma'am, I want to ask something but can I say it in Afrikaans?" My own observations in this school confirm that teachers will use Afrikaans mainly for affective purposes but that learners use code switching extensively to negotiate tasks in group work.

Like bilingual communities, bilingual schools provide an environment where code switching is an everyday occurrence. One student at a bilingual school observes that "the code switching occurs constantly and continuously throughout the lesson with a lot of repetition taking place in order for learners of both languages to fully understand certain concepts" (Jessica PGCE). Another student notes, "at X teachers and learners will recurrently code switch ... to aid the process of mutual understanding, clarity of expression and certainty of meaning" (Kyle PGCE.) 
Student teachers' examples of code switching seem to indicate some convergence with the functions of code switching as described by Auerbach (1993) and Swain and Lapkin (2000) at the start of this section. Negotiating the syllabus takes place in circumstances where code switching is allowed or when learners ask explicitly to use their home languages.

Code switching can also be seen as a way for the teacher to ensure that an instruction is understood well. Pieter (PGCE) reports from an Afrikaans-medium school that the teacher in the English FAL class translates instructions as a matter of course: "Please open your books on page four and read through the paragraph on cell phones. Maak oop julle boeke op bladsy vier en lees daardie paragraaf' [Open your books on page four and read that paragraph]. The use of the demonstrative pronoun (underlined) in the Afrikaans sentence indicates that she expects some comprehension but that the translation is probably done to make doubly sure. My own observation of a BEd student teacher yielded examples of orders and instructions in Afrikaans, even from home language speakers in home language classrooms (which often include substantial numbers of non-home language speakers). In a lesson in which I recorded only three instances of code switching, the student told his class, "Julle het twee minute" [You have two minutes]. The other two instances were directed at a learner who arrived late (see below).

Scene setting was not observed by students, although one student reported that a teacher would re-cap the previous day's reading from a Shakespeare play in Afrikaans, summarising the plot before continuing with the text in English. In one case the student teacher tried to draw out extremely shy grade 5 learners by asking for the names of fruit in Xhosa and then providing the English names and spelling (Fritzi, BEd). In this case one could argue that the scene was set for the topic of going to the market - the theme of the lesson. Auerbach (1993:21) also mentions explanations of errors as an occasion that may prompt code switching. Students did not observe this or did not offer specific examples of such cases.

\subsection{Code switching for affective purposes}

The use of code switching to accommodate or create distance from conversational partners focused both on signalling serious intent with regard to maintaining discipline as well as a more relaxed and personal approach. Both of these functions of code switching are reported on in Auerbach (1993), Cook (2001:415) and Hughes et al. (2006).

In the student teacher reports the use of code switching to maintain discipline predominates. This may just be their perceptions, although a similar finding was reported by Phillips (1975) in Spanish-English interaction, where up to $70 \%$ of teacher code-switching involved discipline-oriented interaction. However, the situation there was one of using the dominant language (English) to marginalise learners' home language. In the South African situation the reverse is true, probably because the majority of English language teachers at the schools where student teachers were placed are Afrikaans-speaking.

As one student who did her practice teaching at an Afrikaans secondary school put it, "they [the teachers] greet, confront and scold the learners in Afrikaans" (Maritsa PGCE). After a fairly lengthy description of a particular teacher's code switching practices, another student comes to the conclusion, "I realised that she usually gives orders in Afrikaans: "Stap uit my klas!" [Get out of my class!], "Bly stil!" [Keep quiet!] or "Doen jou werk!" [Get on with it!] are phrases that are heard regularly in class" (Zandberg PGCE). One student mentioned the 
same use of code switching in an Afrikaans FAL classroom where the teacher switches to English (the home language of the majority of the learners), and the teacher (when interviewed) commented that she thought learners "tended to behave more and were more disciplined" when she switched to English (Kerry PGCE).

In all cases where students interviewed teachers after the class about using code switching to maintain discipline, teachers explained that the use of the L1 signalled the gravity of the situation or the offence. Lize (PGCE) noted specifically that the teacher will first issue a request or order in English "but if the learner did not stop or ignored her, she would switch to Afrikaans, to scold him/her in Afrikaans". A similar point was raised by Phoebe (PGCE) about two teachers of the English home language curriculum: "When the class became extremely disruptive, she would discipline the learners in their mother tongue - she stated in an informal interview that this is the only way some of the learners would pay attention" and, "she only used code switching to discipline some of the learners, this was only implemented if the learners refused to listen". In the one case where the student teacher only switched three times from English to Afrikaans during his lesson (referred to above), two instances were meant to reproach a learner who had arrived late, e.g., "Ons gaan net wag vir die hóófmeisie om haar boek uit te haal" [We'll just wait for the head prefect to take out her book] (Sven $\mathrm{BEd}$ ). (There was clearly some kind of history to the remarks.)

In my observations learners also used their home languages to signal displeasure or anger at other learners or the teacher. In one case the student teacher appointed a learner as a 'talk show host' and when another learner dared to address the teacher he was immediately told, "Roep vir my as jy iets wil sê!!" [Call me if you want to say something!] In another case Xhosa-speaking learners expressed their displeasure with the teacher in Xhosa, not knowing that the student teacher understood them (Kenilwe BEd)!

On a more positive note teachers also use code switching to narrow the gap between them and the learners. My own observations confirmed that switches motivated by accommodation strategies usually took place "off-the-record", when learners were working either in groups or individually. The student teacher would move among them and speak softly in the learners' home language. One student reported that a teacher who was fluent in Xhosa used it "to establish relationships with the learners, using it in a more informal context" even though she never used it "in a formal English lesson" (Elna PGCE). A similar situation is reported in the case of a teacher who used code switching mainly for clarification purposes. However, "when the teacher wants to talk about things that is (sic) not connected with the subject like what will happen in a weeks (sic) time at school, what are your goals in life and life lessons she switches to Afrikaans" (Lizna PGCE). Pieter (PGCE) links a switch to the home language specifically to informal register and interaction between the teacher and learners on an individual basis. Even teachers of home language speakers or, rather learners following the home language curriculum, were reported to switch in these cases: "She promotes speaking only English in her classroom, but as the learners would start to discuss issues and the issues would become personal she would switch to Afrikaans" (Phoebe PGCE). 


\section{DISCUSSION}

It is to be expected that code switching, which is so ubiquitous in bilingual and multilingual communities, will also appear in bilingual classrooms. What is interesting is the degree to which such classroom practice is evidence of a community of practice, to use Wenger's term (2000), where the boundaries have been negotiated and learners know when they may use the home language (when they ask for permission to do so, in group work or when they speak individually and off-the-record to the teacher). Similarly, teachers seem to set boundaries for their use of the home language in English language teaching classes, as became evident in those cases where students followed up their observations by asking teachers about their code switching.

The power of the teacher as the speaker who holds the floor, is undeniable: s/he makes the rules, s/he allows code switching to take place, either by giving permission explicitly or by using it in a specific way her/himself. As the one student observed, "learners would more readily ask me to speak to them in Afrikaans or if they can ask me something in Afrikaans. This usually happens (sic) when the teacher has stepped out of the class" (Ilse PGCE). The student teacher, who does not have the authority of the regular teacher, has not had the chance to set boundaries or establish patterns of code switching.

One student raised the point that teachers seem to code switch more towards the end of classes and towards the end of the day, ascribing this to tiredness of both teacher and learners (Phoebe PGCE). This is an interesting observation that may relate to the psycholinguistic processes involved in code switching, either in terms of the cognitive effort to suppress a very natural phenomenon or in terms of the effort needed to interpret and translate terms and concepts.

The report of student teachers' observations should not create the impression that they supported this practice or that all the teachers they observed, supported the practice. I referred above to one student who thought that code switching was a 'quick fix' (Renier PGCE). Maritsa (PGCE), who is Afrikaans-speaking herself, feels that it is an effective way to "lighten the atmosphere in class" or to explain the vocabulary to them, but that "Afrikaansspeaking English teachers do more harm than good ... they are lazy and do not set a good example for the learners". Some student teachers express their disapproval of this practice because they feel that learners will not develop their competence unless they are pressured into using only English. The home language as a safety net is seen as preventing the development of English. This is an argument that is often used to counter the use of the home language in English language teaching (Cook, 2001:406). Students who are against this practice often use their mentor teachers as positive role models, noting that they have an 'English only policy' in their classroom. Although one can disagree with a blanket condemnation of code switching, such students indicate how the use of the home language can be avoided, referring to elicitation techniques (such as providing the start of the word or synonyms) and the importance of patience to give learners the time to express themselves. Such strategies foster language acquisition and they can be used alongside code switching.

Students also conclude their assignments by recommending a judicious use of code switching and they distinguish between teaching English FAL (for which more code switching may be needed) and home language teaching (where many students felt learners should be sufficiently proficient not to need code switching). 
It seems logical that code switching should be more commonplace in the Intermediate Phase than the Senior Phase or the FET. However, my own observations of BEd students teaching in the Intermediate Phase do not confirm this expectation, probably because I normally have to assess their teaching and they may think (despite reassurances to the contrary) that they should stick to English only. The PGCE students' reports and my observation of Senior Phase and FET teaching did not confirm this expectation either. However, a more detailed investigation is needed to gather data on this aspect.

\section{CONCLUSION}

This overview of code switching presents a small sample of schools and a focus on mainly grades 6-11 teaching, since most schools do not want to place student teachers with their grade 12 learners, who are in the final throes of preparing for the national exit examination. The trends observed by students and me over two years, often in the same schools, do show, however, similarity in the functions and domains of instructional code switching.

The functions of code switching converge to a large extent with those mentioned by Auerbach (1993), Swain and Lapkin (2000), Cook (2001) and Hughes et al. (2006). There are some notable exceptions, which may be due to the students' focus when they observed classes and in my case, the circumstances under which I observed the student teachers: they always presented a specially prepared, isolated lesson of maximum 50 minutes.

Code switching for mainly administrative tasks in the form of record-keeping and classroom management was not mentioned once. Administrative tasks would include noting absences or checking for money that needs to be paid. With classroom management is meant, for example, moving desks, cleaning the classroom or arranging outings for matches to be played. In view of the type of code switching practices discussed above it hardly seems possible that these functions would not have triggered code switching. As mentioned above the use of code switching to explain errors was not noted either.

This type of exploratory research provides only the most basic of guidelines for teacher education and training. At the very least an awareness of code switching should be introduced, if only for the purpose identified by Auerbach (1993:30) when she asserts that "the extent to which ESL educators value participants' linguistic resources in teaching is a measure of our willingness to address basic inequities in the broader society". In a study of the credentialling of teachers in California, Montaño et al. (2005) are concerned about the extent to which negative attitudes towards home- and community languages may result in "debilingualising teachers" and fostering language loss among their learners (2005:104). I do not suggest that Afrikaans (in the school contexts where student teachers from Stellenbosch University usually go) is necessarily a minority language, but an awareness of the value of code switching is valid in the case of all low status languages as well as so-called nonstandard varieties of high status languages.

Convincing student teachers of the validity of code switching in language teaching in particular will have to rely on the kind of research produced by Swain and Lapkin (2000), where their detailed observations of code switching among English learners of French in an immersion setting prove that the judicious use of code switching supports rather than subverts language learning and teaching: "For this reason, the use of the L1 should not be prohibited in immersion classrooms, but neither should it be actively encouraged as it may substitute for, 
rather than support, second language learning" (2000:268). This kind of evidence may convince those student teachers who think that code switching is only used for intractable learners by lazy teachers who cannot speak English!

\section{REFERENCES}

AUERBACH, E.R. 1993. Reexamining English only in the ESL classroom. TESOL Quarterly, 27(1): 9-32.

BECKER-MROTZEK, M. \& VOGT, R. 2001. Unterrichtskommunikation: Linguistische Analysemethoden und Forschungsergebnisse. [Classroom communication: linguistic analysis, methods and research findings.] Series: Germanistische Arbeitshefte 38. Tübingen: Max Niemeyer.

COOK, V. 2001. Using the first language in the classroom. The Canadian Modern Language Review/La revue canadienne des langues vivantes, 57(3): 402-423.

CUMMINS, J. 2008. From compound and coordinate bilingualism to multicompetence and multiliteracies: Challenging dogma or embracing heresies? Plenary presented at an international conference on Language issues in English-medium universities: A global concern, held at the University of Hong Kong, 18-20 June.

FERGUSON, G. 2006. Language planning and education. Edinburgh: Edinburgh University Press.

HUGHES, C.E., SHAUNESSY, E.S., BRICE, A.R., RATLIFF, M.A. \& MACHATTON, P.A. 2006. Code switching among bilingual and limited English proficient students: Possible indicators of giftedness. Journal for the Education of the Gifted, 30(1):7-28.

LANGUAGE IN EDUCATION POLICY. 1997. Pretoria: Department of Education. [Online] Available: http://www.education.gov.za/Documents/policies/LanguageEducationPolicy1997.pdf [2009, June 17].

LANGUAGE, LITERACY AND COMMUNICATION. 1997. Pretoria. Department of Education.

LOFLAND, J. 2002. Analytic ethnography: Features, failings and futures. In Huberman, A.M. \& Miles, M.B. (eds.). The qualitative researcher's companion. London: Sage Publications. 137- 170.

MATI, X. 2004. Using code switching as a strategy for bilingual education in the classroom. Paper presented at the 21st annual AEAA Conference, 25-28 August, HSRC, Pretoria. [Online] Available: www.umalusi.org.za/ur/Conferences/AEAA/Mati\%20X.PDF [2009, February 15].

MILES, M.B. \& HUBERMAN A.M. 1994. Qualitative data analysis. $2^{\text {nd }}$ edition. Thousand Oaks: Sage.

MONTAÑO, T., ULANOFF, S.H., QUINTANAR-SARELLANA, R. \& AOKI, L. 2005. The debilingualization of California's prospective bilingual teachers. Social Justice, 32(3): 103-121.

NCS ENGLISH FIRST ADDITIONAL LANGUAGE. 2003. Pretoria: Department of Education. 
PHILLIPS, J.M. 1975. Code-switching in bilingual classrooms. ERIC Document Reproduction Service No. ED 111222.

PLÜDDEMANN, P., BRAAM, D., BROEDER, P., EXTRA, G. \& OCTOBER, M. 2004. Language policy implementation and language vitality in Western Cape primary schools. University of Cape Town: PRAESA Occasional Papers No. 15.

REVISED NATIONAL CURRICULUM STATEMENT GRADES R-9. 2002. Pretoria: Department of Education.

SEEDHOUSE, P. 2005. Conversational analysis and language learning. Language Teaching, 38: $165-187$.

SETATI, M., ADLER, J., REED, Y. \& BAPOO, A. 2002. Incomplete journeys: Codeswitching and other language practices in Mathematics, Science and English language classrooms in South Africa. Language and Education, 16(2): 128-149. Available: http://www.multilingual-matters.net/le/016/0128/le0160128.pdf [2008, February 29].

SWAIN, M. \& LAPKIN, S. 2000. Task-based second language learning: the uses of the first language. Language Teaching Research 4(3): 251-274

TARONE, E. \& SWAIN, M. 1995. A sociolinguistic perspective on second language use in immersion classrooms. Modern Language Journal, 79: 24-46.

ÜSTÜNEL, E \& SEEDHOUSE, P. 2005. Why that, in that language, right now? Codeswitching and pedagogical focus. International Journal of Applied Linguistics 15 (3): 302-325.

VAN DER WALT, C. 1997. English as a language of learning in South Africa: Whose English? Whose culture? Language Awareness, 6(2\&3): 183-197.

VAN DER WALT, C., MABULE, R. \& DE BEER, J.J. 2001 Letting the L1 in by the back door: Code switching and translation in Science, Mathematics and Biology classes. Journal of Language Teaching, 35(2\&3): 123-134.

WENGER, E. 2000. Communities of practice and social learning systems. Organisation, 7(2): 225-246.

\section{BIOGRAPHIC NOTE}

Prof Christa van der Walt is head of the Department of Curriculum Studies.

(Email: cvdwalt@sun.ac.za)

\footnotetext{
${ }^{\mathrm{i}}$ See for example the English Revised National Curriculum Statement Grades R-9, 2002:4 and National Curriculum Statement grades 10-12, 2003:9.

ii The information provided about schools cannot be too specific so that the schools cannot be identified.
} 